\title{
NBS
}

Eechnical Note no.8

\section{THERMODYNAMIC PROPERTIES OF} HELIUM AT LOW TEMPERATURES AND HIGH PRESSURES

BY D. B. MANN AND R. B. STEWART

U. S. DEPARTMENT OF COMMERCE NATIONAL BUREAU OF STANDARDS 



\section{NATIONAL BUREAU OF STANDARDS Eechnical Mote}

May 1959

THERMODYNAMIC PROPER TIES OF HELIUM AT

LOW TEMPERATURES AND HIGH PR ESSURES

by

D. B. Mann and R. B. Stewart

The data presented in this report is part of a study made under contract with Bureau of Aeronautics, Department of the Navy.

NBS Technical Notes are designed to supplement the Bureau's regular publications program. They provide a means for making available scientific data that are of transient or limited interest. Technical Notes may be listed or referred to in the open literature. They are for sale by the Office of Technical Services, U. S. Department of Commerce, Washington 25, D. C.

DISTRIBUTED BY

UNITED STATES DEPARTMENT OF COMMERCE OFFICE OF TECHNICAL SERVICES

WASHINGTON 25, D. C.

Price $\$ 1.25$ 



\section{ACKNOW LEDGEMENTS}

The data presented in this report is part of a study made under contract with Bureau of Aeronautics, Department of the Navy. 'The substance of this report was presented for the Degree of Master of Science, Mechanical Engineering at the University of Colorado (1959) under the title of "Thermodynamic Properties of Helium at Low Temperatures and High Pressures" by Douglas B. Mann.

Sections of this data have been submitted to the American Society of Mechanical Engineers for presentation at the National Heat Transfer Conference at Storrs, Connecticut. 

TABLE OF CONTENTS

PAGE

INTRODUCTION

8.

SYMBOLS

7.

PRESENT DATA

8.

MORE RECENT DATA

9.

CORRELATION OF DATA

9.

CALC ULATION OF ISOBARS

13.

CALCULATION OF ISENTHALPIC CURVES

17.

LOUNASMAA'S EXPERIMENTAL AND DERIVED DATA

17.

CONCLUSIONS

24.

BIB LIOGRAPHY

26.

APPENDIX

28.

Derived Functions and Diagram Construction

29.

Associated Thermodynamic Property Charts

34. 



\section{LIST OF FIGURES}

1 Specific Heat at Saturation of Liquid Helium

12. Illustrating the Method Used to Determine the Absolute Entropy of Liquid Helium at the Normal Boiling Point

2 Specific Heat at Saturation of Liquid Helium 14. Illustrating the Method Used to Calculate $\int \mathrm{C}$ sat. d T Employed to Determine the Absolute Enthalpy of Liquid Helium at the Normal Boiling Point Illustrating the Calculation of $\int \mathrm{V} d \mathrm{P}$ Used in Determining the Enthalpy at the Normal Boiling Point

Enthalpy-Entropy Diagram of Helium

Temperature-Entropy Diagram of Helium

22.

Isotherms of Helium as Functions of Volume 30 . and Entropy

8 Slopes of Isotherms of Figure 7 Illustrating the 32. Method Used to Determine Isobars

9 Pressure-Temperature Diagram of Helium Illustrating the Method Used to Determine Enthalpy Values 

12 Pressure-Internal Energy Diagram for Helium.

0 to 100 Atmospheres.

13 Specific Heat at Constant Pressure of Helium Gas

38.

14 Compressibility Factor Z for Helium Gas.

39. 

5.

\section{LIST OF TABLES}

TABILE

PAGE

I Pressure Reference Points

16.

II Comparison of Values of $\left(\frac{\partial P}{\partial T}\right)_{V}$

19.

III Entropy of Fluid Helium

31. 



$$
6 .
$$

\section{THERMODYNAMIC PROPERTIES OF HELIUM AT LOW}

TEMPERATURES AND HIGH PRESSURES

\section{by}

Douglas B. Mann and Richard B. Stewart

\section{ABSTRACT}

The most comprehensive investigations of the thermodynamic properties of normal helium I and II were published over a period of the last thirty years by W. H. Keesom. A culmination of most of this work was published by Keesom in 1942. Since that time, numerous investigators have found several discrepancies in this original work in the temperature range below $20^{\circ} \mathrm{K}$. Recent interest in the compressed liquid region, an area not covered extensively by Keesom's work has resulted in new experimental data. These investigations and corrections to Keesom's work have been published, not as additions to the original Keesom work, but as separate and sometimes isolated articles of very narrow interest and not in readily usable form. Also the new data have little value until their relation to existing data is established.

This thesis is a compilation and correlation of the present data on the thermodynamic properties of helium below $20^{\circ} \mathrm{K}$. The existing data were compared to the new data and the errors resolved by selection based on estimated accuracy, experimental apparatus, and technique of the investigator.

Methods of property diagram construction are also explained, and the results are presented in the form of temperature-entropy and enthalpy-entropy diagrams. Pressures to 100 atmospheres, temperatures from $0^{\circ} \mathrm{K}$ to $20^{\circ} \mathrm{K}$ and specific volumes from 5 liter $\mathrm{s} / \mathrm{kgm}$. to 800 liters $/ \mathrm{kgm}$. are presented. 



\section{SYMBOLS}

The following symbols were used in the thesis:

$\mathrm{C}_{\text {sat. }}$ Specific heat of liquid helium at saturation conditions, joules/gram $-{ }^{\circ} \mathrm{K}$.

ho Enthalpy of helium at zero degrees Kelvin. calories/gram.

h Enthalpy of helium, calories/gram.

P Pressure, atmospheres.

s. Entropy of Helium at zero degrees Kelvin, calories/gram $-{ }^{\circ} \mathrm{K}$.

s Entropy of helium, calories/gram $-{ }^{\circ} \mathrm{K}$.

T Temperature, degrees Kelvin.

v. Specific volume of helium, liters/kilogram.

$\rho \quad$ Density of Helium, grams $/ \mathrm{cm}^{3}$.

$P_{c} \quad$ Critical Density of Helium, $0.0693 \mathrm{grams} / \mathrm{cm}^{3}$.

$\rho *$ Reduced Density of Helium $=\frac{\rho}{\rho_{C}}$. 



\section{INTRODUCTION}

The compilation of the thermodynamic properties of helium involves the summarization and correlation of large quantities of sometimes isolated information, both theoretical and experimental, into a composite form. The properties of vapor, liquid and solid phases are not usually investigated by one single experimenter or team; and in general each investigation concerns only an isolated region dictated by technical demands or the investigator's particular curiosity.

New experimental information must be correlated carefully with existing data so that the result reflects an accurate compilation of the properties under investigation.

The object of this paper is to construct diagrams of properties for helium which incorporate recent experimental findings in the region of the compressed liquid state.

The resulting diagrams will include the thermodynamic properties of pressure, volume, temperature, enthalpy and entropy for pressures up to 100 atmospheres, specific volumes from 5 to 800 liters per kilogram and temperatures from $3.0^{\circ} \mathrm{K}$ to $20^{\circ} \mathrm{K}$.

\section{PRESENT DATA}

The greatest quantity of technical information prior to 1952 on the physical properties of helium in the region under investigation comes from two sources.

1) A compilation by W. H. Keesom ${ }^{(6)}$ of the theoretical and experimental investigations performed at the University of Leiden, Holland. This work is very extensive and covers the temperature range from $0^{\circ} \mathrm{K}$ to $400^{\circ} \mathrm{K}$ and pressures from 0.001 atmospheres up to 200 atmospheres.

2) An investigation of the Joule-Thomson effect in helium by J. Zelmanov(13). This work resulted from discovery of discrepancies found in Keesom's work by Peter Kapitza while he was constructing a helium liquefier. Kapitza suggested that an error existed in the Joule-Thomson inversion point values of Keesom's at temperatures below $20^{\circ} \mathrm{K}$. Zelmanov, a colleague of Kapitza, experimentally investigated this temperature region in respect 
to the Joule-Thomson effect and published a revised temperature-entropy diagram of helium below $20^{\circ} \mathrm{K}$, incorporating his findings $(2)$. The Zelmanov data covered the temperature range from $0^{\circ} \mathrm{K}$ to $20^{\circ} \mathrm{K}$ and pressures from 0.5 atmospheres to 60 atmospheres.

\section{MORE RECENT DATA}

R. W. Hill presented new experimental data (3) (5) in the region from the critical pressure of 2.2 atmospheres to 100 atmospheres and at temperatures from $2.5^{\circ} \mathrm{K}$ to $20^{\circ} \mathrm{K}$. These data from Hill were given in terms of temperature, specific volume and entropy. To make this information more useful, it was necessary to determine pressure and enthalpy values from Hill's data and plot these derived results using the existing Keesom-Zelmanov diagram as a reference.

Some months after these data had been received and the derived functions calculated and plotted, the author secured a copy of a doctoral thesis by O. V. Lounasmaa (9) in which the data of Hill, Lounasmaa's thesis supervisor, were presented in addition to experimental values of pressure. These data covered the same temperature, specific volume and pressure ranges as Hill's data.

Recent efforts to agree on an international vapor pressure-temperature scale for helium have resulted in several articles on this temperature scale. Berman and Mate(l) and Van Dijk and Durieux $(11)$ have presented extensive data on temperature, vapor pressure, satur ation densities and heats of vaporization.

C. Domb and J. S. Dugdale ${ }^{(2)}$ have recently presented a summation and extension of experimental data dealing with the solid phase for pressures ranging from 25 atmospheres to 225 atmospheres and temperatures from $0^{\circ} \mathrm{K}$ to $6^{\circ} \mathrm{K}$.

\section{CORRELATION OF DATA}

The experimental data of Hill and Lounasmaa and the derived results of this paper include the region bounded by the KeesomZelmanov properties of saturated and slightly compressed liquid and the data of Domb and Dugdale concerning the properties of the solid phase. 
The temperature-entropy coordinates of thermodynamic properties of helium are commonly used by engineers for investigation of liquefaction or refrigeration cycles and the design of heat exchange equipment. The properties of the compressed liquid phase can be plotted on this coordinate system to show the general behavior trends, but the plot proves unsatisfactory for calculation purposes because at high pressures, the slopes of the constant temperature, pressure and enthalpy lines are approaching a common value, making interpolation difficult and inaccurate.

The enthalpy-entropy plot is generally used to express the properties of compressed fluids $(10)$ and has the advantage of large differ ences in the slopes of the isotherms, isochores, and constant enthalpy lines.

It was therefore decided to express the results of this compilation on both coordinate systems; thus this new information will be useful for cycle analysis by plotting the data on temperature-entropy coordinates, while calculations in the compressed liquid state can be made by referring to the data plotted on enthalpy-entropy coordinates.

When constructing the above plots, it was necessary to establish the entropy and enthalpy of some fixed point as a reference. The data of the several investigators could then be referred to this fixed point for correlation. The normal boiling point of liquid helium was selected as the fixed reference point even though no such point is contained in the solid-liquid equilibrium data of Domb and Dugdale. The entropy difference between the solid-liquid equilibrium at the normal boiling point temperature and the saturated liquid at the same temperature was determined in the following manner.

A presently agreed upon interpretation of the Nernst-Simon Statement of the Third Law of Thermodynamics $(6)(14)$ s tates that the absolute entropies of the solid at $0^{\circ} \mathrm{K}$ and 25 atmospheres pressure and of the saturated liquid at zero degrees Kelvin and zero pressure are identically equal to zero. Therefore, we have only to establish the entropy difference between the saturated liquid at zero temperature and pressure and the saturated liquid at the normal boiling point of $4.21 \mathrm{~K}^{(15)}$ and one atmosphere pressure in order to determine the absolute entropy of the liquid at the normal boiling point. 


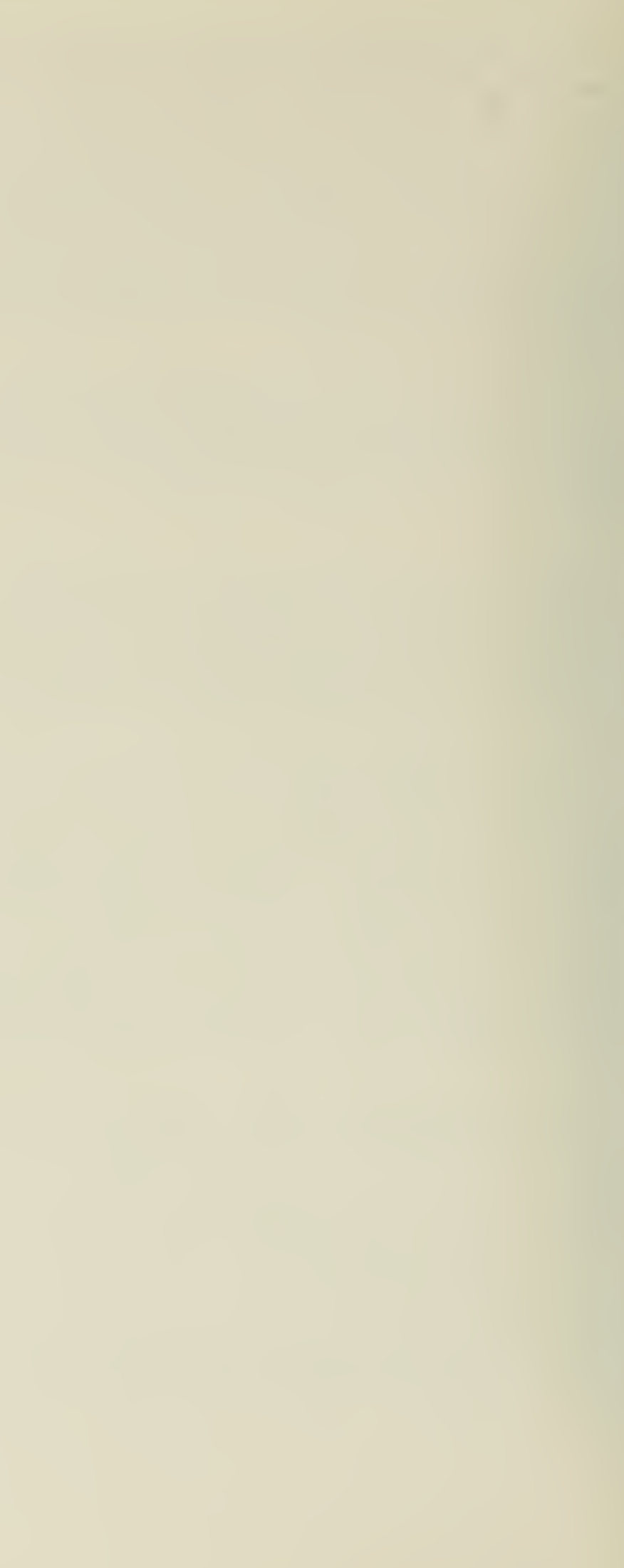


If the specific heat of the saturated liquid is known, the entropy difference between any two temperatures can be expressed as

$$
S_{2}-S_{1}=\int_{T_{1}}^{T_{2}} \frac{C_{\text {sat }}}{T} d T
$$

Therefore, when $\mathrm{T}_{1}$ is equal to absolute zero and $\mathrm{T}_{2}$ is equal to $4.21^{\circ} \mathrm{K}$ the integral will be equal to the entropy difference between absolute zero and the normal boiling point.

The values of $\mathrm{C}_{\text {sat. }}$ from the data of Kramers, Wasscher and Gorter ${ }^{(8)}$ were used to calculate entropy differences below $1.9^{\circ} \mathrm{K}$, while the values of $\mathrm{C}_{\text {sat. }}$ between $1.9^{\circ} \mathrm{K}$ and $5.05^{\circ} \mathrm{K}$ are from data of Hill and Lounasmaa $(4)$. Figure 1 is the plot of $\mathrm{C}_{\text {sat. }} / \mathrm{T}$ versus temperature. The phase change at $2.174^{\circ} \mathrm{K}^{(4)}$ indicated on the curve by a discontinuity at that temperature is the Lambda point transition. This is a second order phase change with no discontinuity in entropy or volume and therefore does not affect the calculation.

The entropy difference between zero degrees Kelvin and the normal boiling point, $S-S_{0}$, as determined from this plot by graphical integration was 0.830 calories $/$ gram $^{\circ} \mathrm{K}$. This value is in agreement with the value of Lounasmaa (9).

We may now plot the data of Zelmanov and Domb et. al. on temperature-entropy or enthalpy-entropy coordinates with a common entropy scale.

Because the Hill data overlaps the Zelrnanov data, it was a simple matter to establish a common reference point between the two.

The fixed point for enthalpy was also selected at the normal boiling point of liquid helium. This value of $2.39 \mathrm{calories}$ per $\mathrm{gram}$ was calculated using the relation

$$
h-h_{0}=\int_{T_{0}}^{T} C_{\text {sat }} d T+\int_{P_{0}}^{P} V d P
$$



Page 12 .

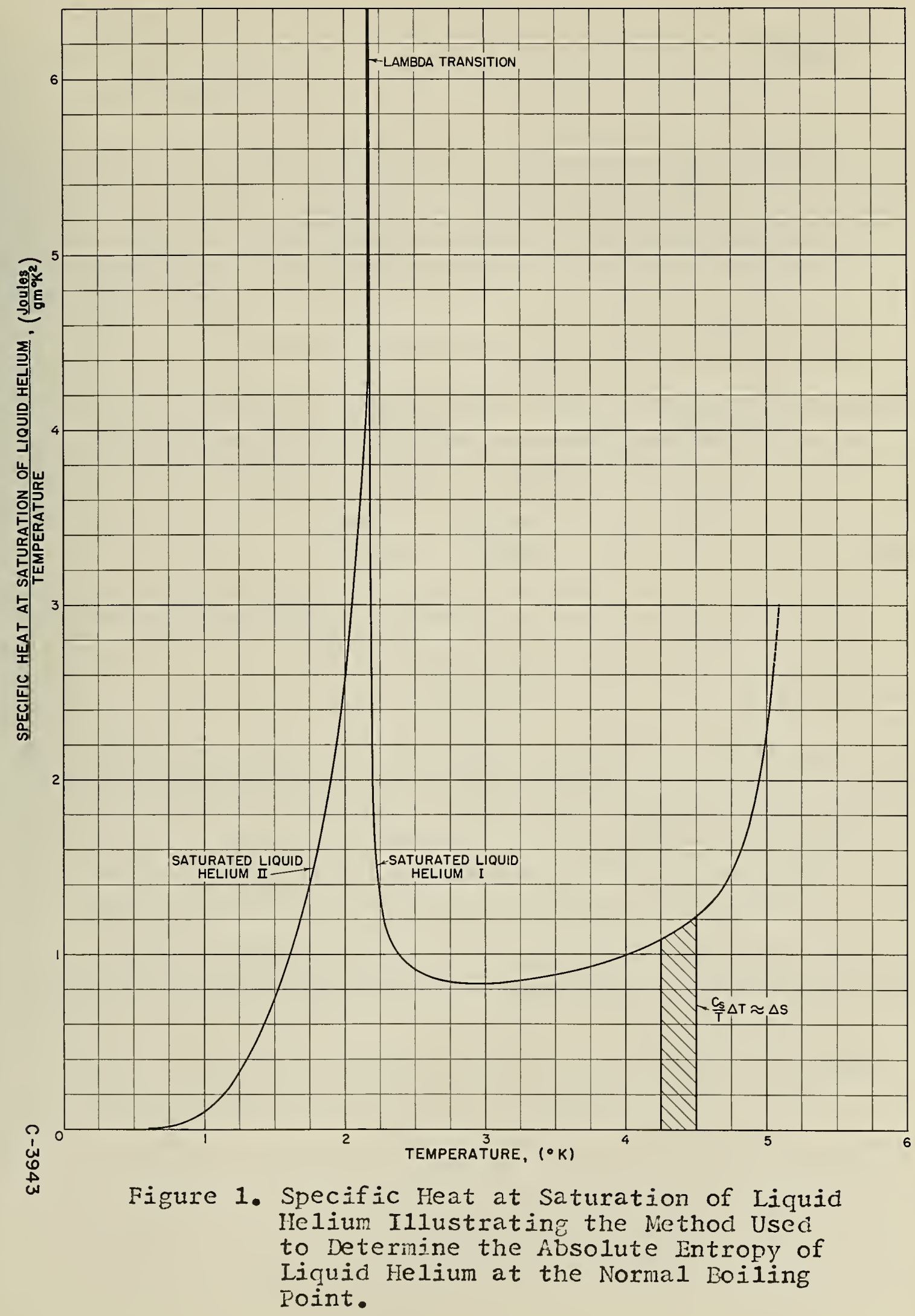



Figures 2 and 3 show the plots of the se two additive functions. The graphical integration results in the required value of enthalpy at the normal boiling point.

The properties of helium given by Hill $(3$ or 5$)$ (Temperature, spe$c$ ific volume, entropy) do not by themselves form a thermodynamically complete set of data necessary for a temperature-entropy or enthalpyentropy diagram. Thus it was necessary to determine pressure and enthalpy using suitable thermodynamic relations and procedures described below.

\section{CALCULATION OF ISOBARS}

With the properties of temperature, specific volume, and entropy, it is possible to determine the lines of constant pressure on the two selected coordinate systems from the Maxwell relation

$$
\left(\frac{\partial S}{\partial V}\right)_{T}=\left(\frac{\partial P}{\partial T}\right)_{V}
$$

which for neighboring states becomes

$$
\Delta P_{V} \approx\left(\frac{\Delta S}{\Delta V}\right)_{T} \Delta T_{V}
$$

Only the pressure differences along the isochores of 5, 5.5,6,7 and 8 liters per kilogram were used for this purpose, as the Zelmanov data adequately described the isochores for larger values up to 800 liters per kilogram. The data for the isochores of 7 liters per kilogram to 70 liters per kilogram of Hill and Zelmanov coincided with those calculated and therefore established the compatibility of data.

Pressure reference points were required for the isobars as the integration resulted in pressure differences only. Table I shows these points.

Sample calculations included in the appendix illustrate in detail the methods employed in calculating the isobars. 

Page 14

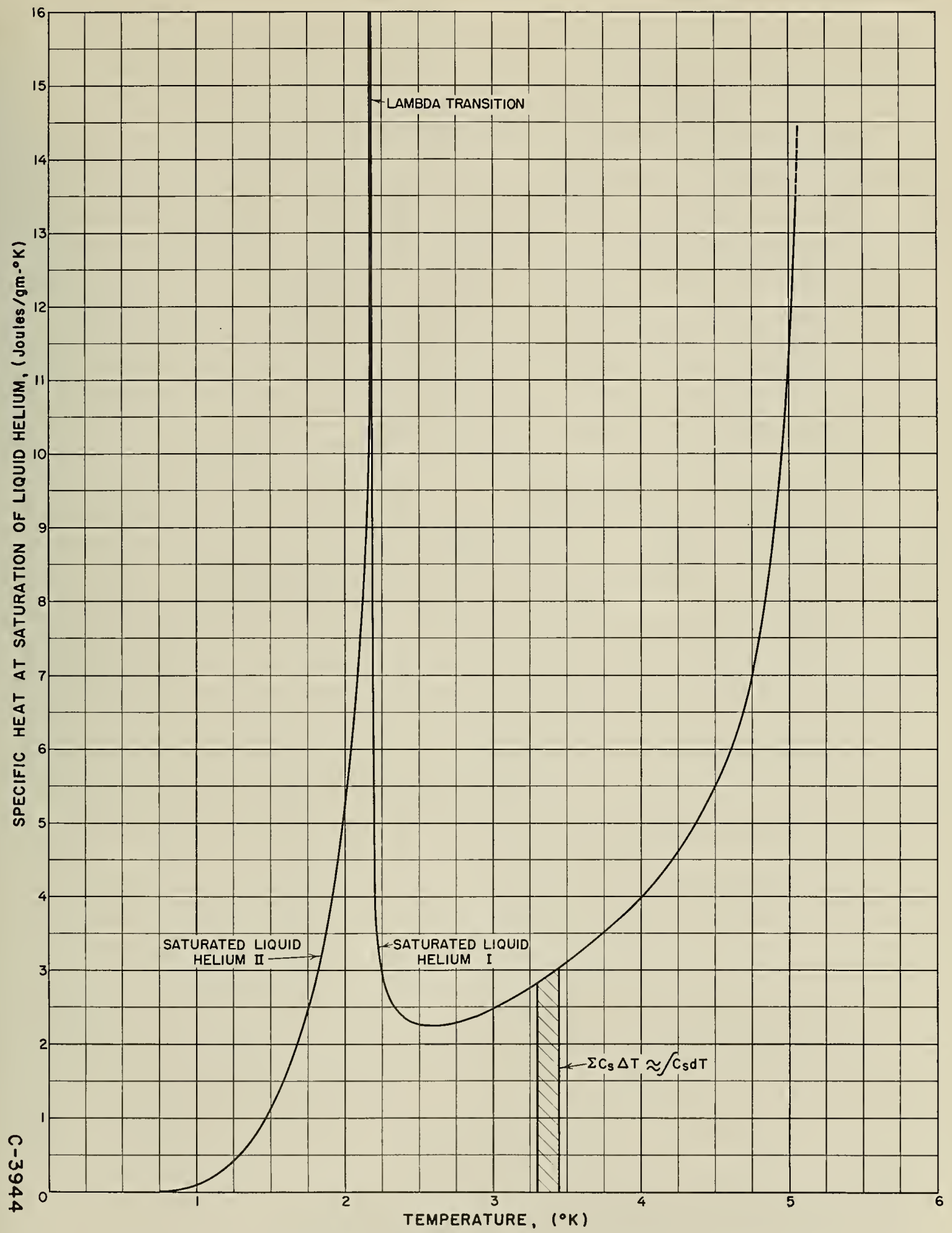

Figure 2. Specific Heat at Saturation of Liquid Velium Illustrating the Method Used to Calculate $\int \mathrm{C}_{\text {sat }} \mathrm{dT}$ Employed to Determine the Absolute Enthalpy of Liquid Yelium at The Normal Boiling Foint. 

Page 15.

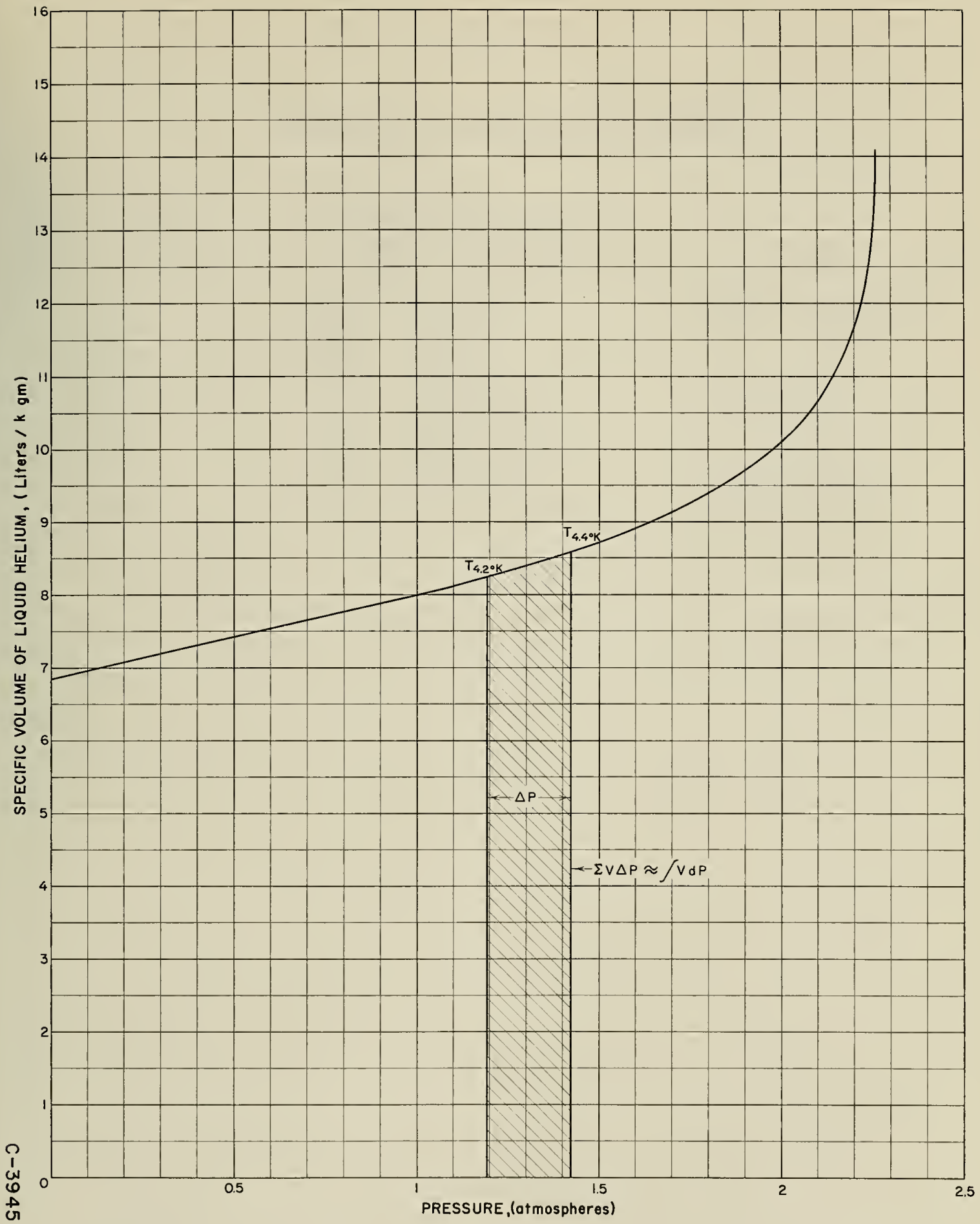

Figure 3. Specific Volume of Saturated Liquid Helium Illustrating the Calculation of J dp Used in Determining the Enthalpy at the Normal Boiling Point. 

TAB LE I

PRESSURE REFERENCE POINTS

Liquid

Specific volume

(Liters/Kgm.)

Saturation pressure

(Atmospheres)

Source
5.00
5.25
5.50
6.50
7,00
8.00

68.8

(Solid)

48.0

(Solid)

33.0 (Solid)

15.0

(Helium II)

4.7

(Helium II)

0.237 (Helium I)

1.0

(Helium I)

Domb, Dugdale ${ }^{(2)}$

it

Keesom ${ }^{(1)}$

Berman (i)

Zelmanov 

As stated above, the normal boiling point of $4.21^{\circ} \mathrm{K}$ and one atmosphere saturated liquid is considered as the fixed reference point for enthalpy. The enthalpy change can be described by the relation

$$
d h=T d S+V d P
$$

Becausc enthalpy reference points were not available except at or near the saturated liquid condition, it was necessary to establish valucs of enthalpy for several pressures in the compressed liquid region. This was accomplished by using an isentropic process and the calculation of enthalpy differences with changes in pressure at constant specific volume,

$$
d h=\operatorname{VdP} \quad(s=c)
$$

The enthalpy of the normal boiling point serves as the datum, and enthalpy values were determined at various pressures along an isentropic through this point up to and including 100 atmospheres pressure.

At the se derived enthalpy points, changes in enthalpy at constant pressure were calculated from equation (5) by

$$
d h=\operatorname{TdS}(p=c)
$$

\section{LOUNASMAA'S EXPERIMENTAL AND DERIVED DATA}

The doctoral the sis of Lounasmaa, "Specific Heats at Low Temperatures" 19$)$ reported in detail the very comprehensive and thorough experiments conducted by Lounasmaa to determine the specific heats and equation of state of liquid helium. The experimental area of investigation included temperatures of from $2.5^{\circ} \mathrm{K}$ to $20^{\circ} \mathrm{K}$, pressures from 2 atmospheres to 100 atmospheres and specific volumes from 4.81 liters per kilogram to 72.15 liters per kilogram. This paper came to the authors' attention after the calculation of isobars had been completed and therefore served as a valuable comparison between derived and experimental data. 
The experimental measurements of Lounasmaa of $P, V, T$ and specific heat eliminated the differentiation step in deriving the pressure differences at constant volume as performed by the author. Since this process of determining the slopes of isotherms on specific volumeentropy coordinates is inherently inaccurate, the derived pressure functions of the author are considered in error when found in conflict with the experimental pressure data of Lounasmaa.

Table II shows the comparison of the calculated slopes of $\left(\frac{\partial P}{\partial T}\right)_{V}$ as determined by the author and experimentally by Lounasmaa. The specific volume is 6 liters per kilogram.

The experimental data of Lounasmaa for the functions of pressure and the derived functions of enthalpy are believed to be of greater accuracy than the derived functions of the author, and therefore the temperatureentropy and enthalpy-entropy diagrams were plotted using this more accurate data. 

TABLE II

COMPARISON OF VALUES OF $\left(\frac{d P}{d T}\right)_{V}$ FOR

\begin{tabular}{|c|c|c|c|}
\hline $\begin{array}{c}\text { Temperature } \\
\left({ }^{\circ} \mathrm{K}\right)\end{array}$ & $\begin{array}{c}\left(\frac{d P}{d T}\right)_{V}(\operatorname{Mann}) \\
\left(\text { atm. } /{ }^{\circ} \mathrm{K}\right)\end{array}$ & $\begin{array}{c}\left(\frac{d P}{d T}\right)_{\text {v Lounasmaa }} \\
\left.\text { (atm. } /{ }^{\circ} \mathrm{K}\right) \\
\end{array}$ & $\begin{array}{c}\text { Error } \\
(\%)\end{array}$ \\
\hline 3.0 & $3.56 *$ & 3.94 & -9.6 \\
\hline 3.5 & 4.36 & 4.50 & -3.2 \\
\hline 4.0 & 4.84 & 4.97 & -2.7 \\
\hline 4.5 & 5.22 & 5.37 & -2.8 \\
\hline 5.0 & 5.52 & 5.70 & -3.2 \\
\hline 6.0 & 5.94 & 6.19 & -4.1 \\
\hline 7.0 & 6.20 & 6.51 & -4.8 \\
\hline 8.0 & 6.38 & 6.72 & -5.1 \\
\hline 10.0 & 6.62 & 6.95 & -4.8 \\
\hline 12.0 & 6.78 & 7.05 & -3.8 \\
\hline
\end{tabular}

* extrapolated value 
Figure 4 is an enthalpy-entropy diagram for helium. The graph was not extended to low pressures and high temperatures as the Zelmanov temperature-entropy diagram is adequate in this region.

Figure 5 is the plot on temperature entropy coordinates of all data discussed in this paper.

An interesting plot of the Lounasmaa and Domb et. a1. data is shown in Figure 6. The isochores of Lounasmaa terminate with respect to data very near the saturated liquid for solidification data of Domb. But to extrapolate the Lounasmaa isochores to an intersection with the saturation boundary necessitates a rapid change in slope of the isochores and in the case of the higher pressures the slope of the isochores must change from positive to negative. This suggests an error either in Domb's saturation data or in Hill's data near saturation.

The origin of the various data plotted in Figures 4 and 5 is as follows:

1) Saturated Liquid for Vaporization. Values of entropy from $0^{\circ} \mathrm{K}$ to $1.9^{\circ} \mathrm{K}$ are from the graphical integration of $\mathrm{C}_{\text {sat. }}$ versus $\mathrm{T}$ of this paper and the

$$
\frac{\text { sat. }}{\mathrm{T}}
$$

data of Kramers et. al. From the lambda point to $5.05^{\circ} \mathrm{K}$ the entropy values of $\mathrm{Hill}$ and Lounasmaa $(4)$ were used. The critical point entropy was found consistent with the value indicated by Zelmanov (12).

2) Saturated Vapor. The heats of vaporization of Berman (1) were used to calculate this boundary. Data of Berman was also used to determine the densities of the liquid and gases at saturation.

3) Saturated Liquid for Solidification. The Domb and Dugdale daca were used for this boundary as vell as the Saturated Solid Boundary.

4) Lambda Transition. From Keesom (6).

5) Isobars. Pressures of 0.5 atmospheres to 3 atmos pheres were from Zelmanov (12). Pressures from 3 atmospheres to 100 atmospheres vere from Lounasmaa(9). 
. 
Fage 21

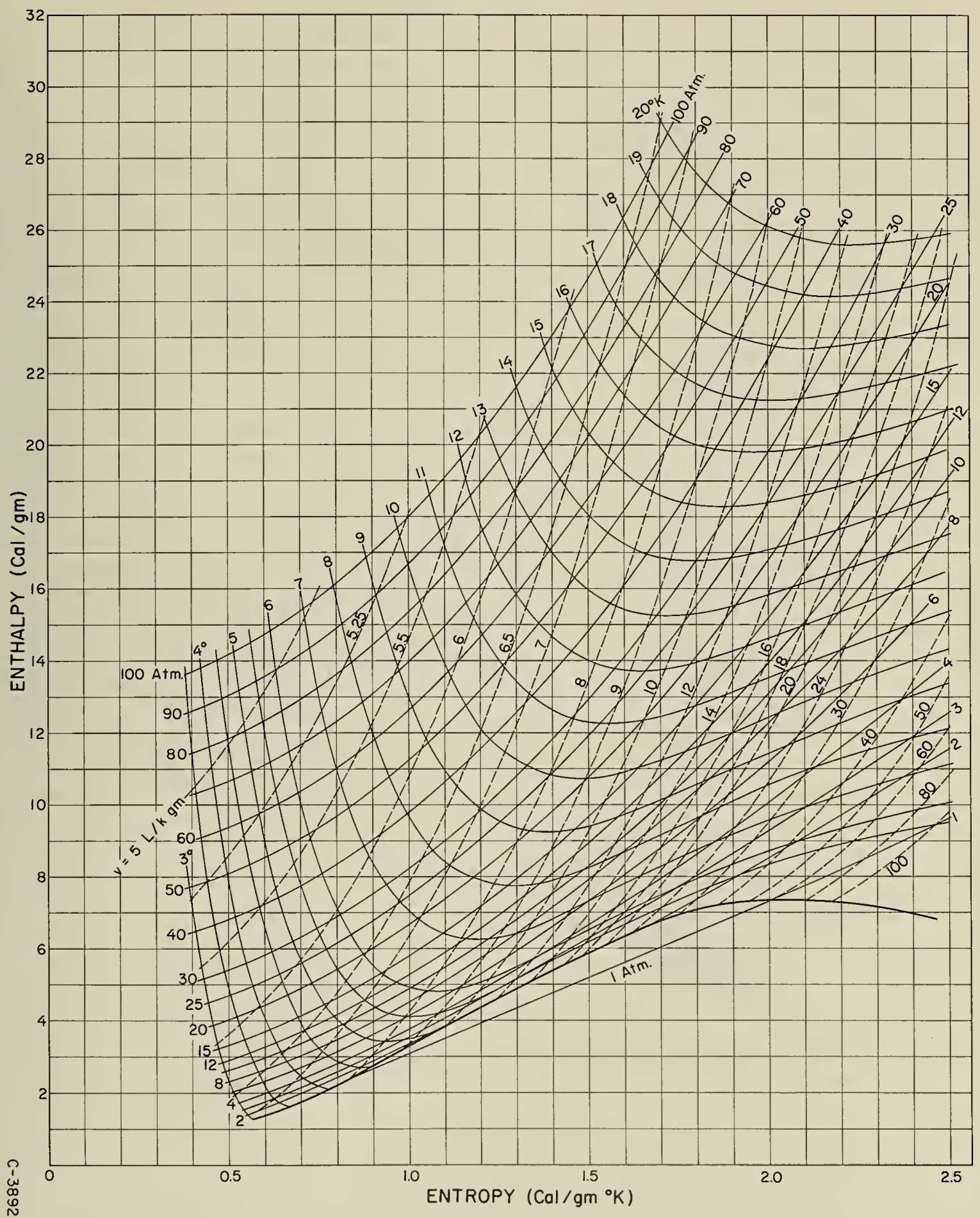

Figure 4. Enthalpy-Entropy Diagram of Helium 

Page 22.

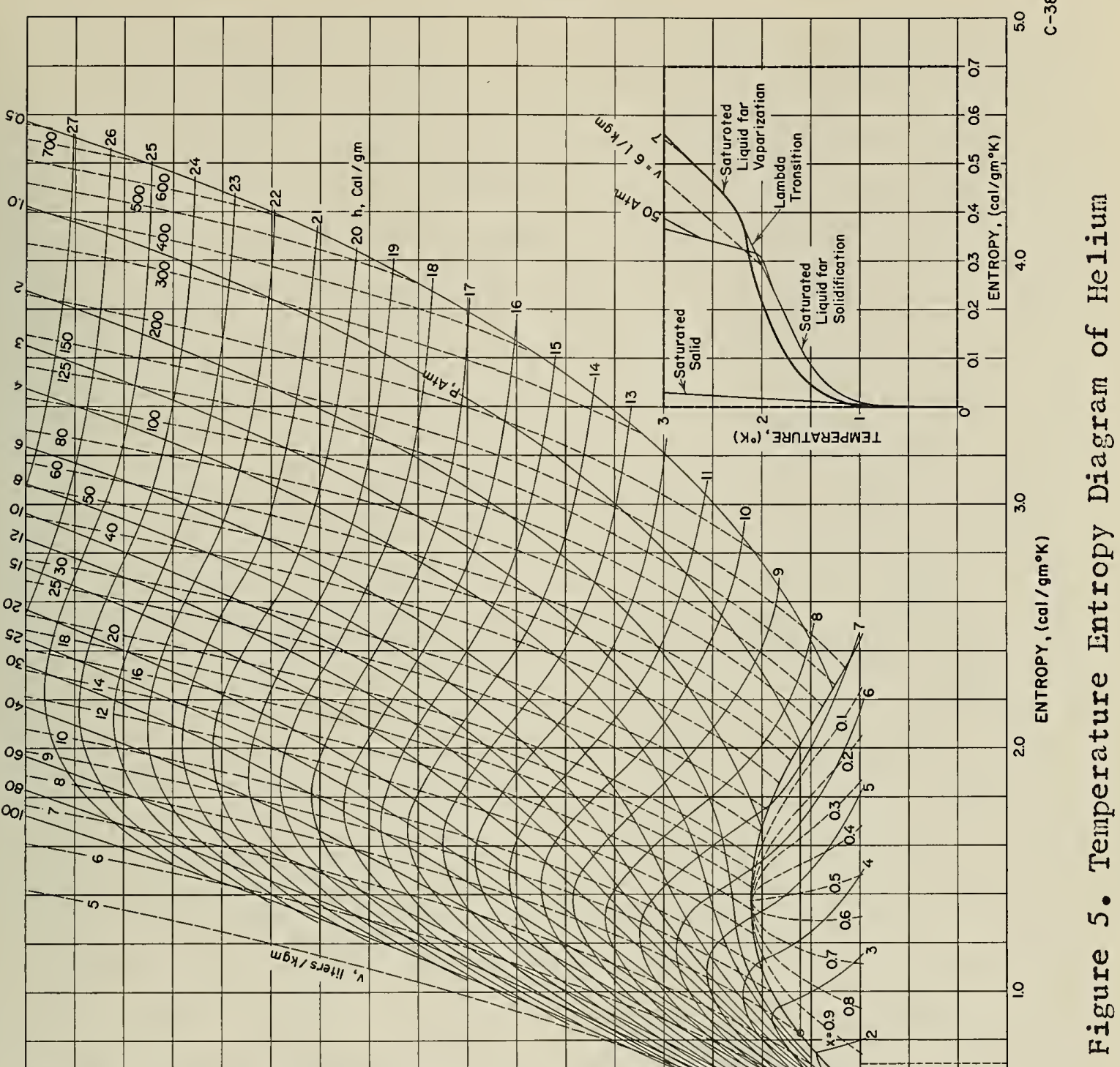



page 23

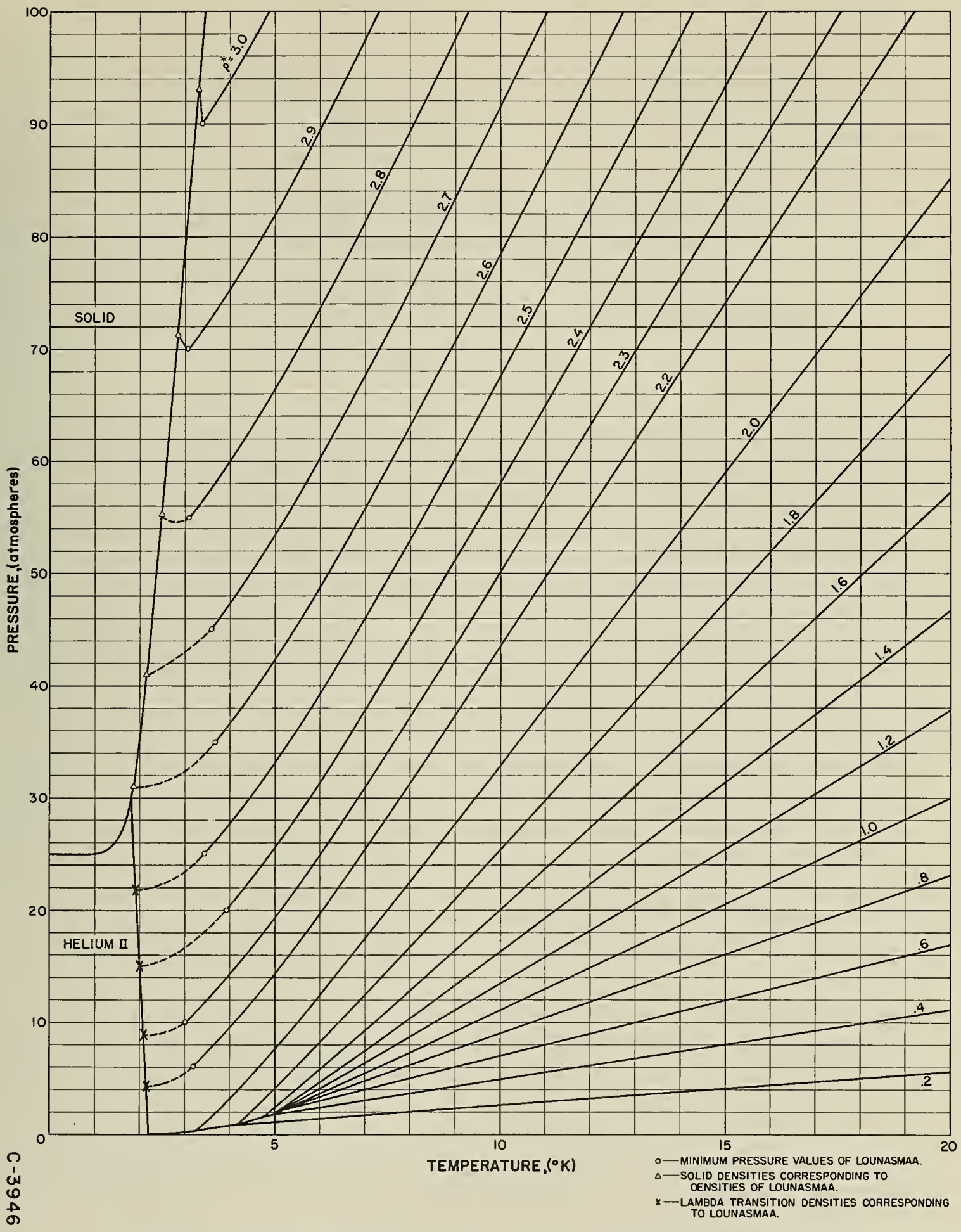

Figure 6. Pressure-Temperature Diagram of Helium 

6) Isochores. Specific volumes of 5 liters per kilogram to 70 liters per kilogram were from Lounasmaa and from 70 liters per kilogram to 800 liters per kilofram were from Zelmanov(12).

7) Enthalpy. Below 2 atmospheres the temperature, pressure, entropy, enthalpy, and density data of Zelmanov (12) were used and from 2 atmospheres to 100 atmospheres the data of Lounasmaa $(9)$ were used.

\section{CONCLUSIONS}

The processes of plotting new experimental data and calculated values derived from this new data using existing reference material subjects the final result to some inherent form of error. The early work of Keesom below $3.5^{\circ} \mathrm{K}$ is subject to error because of changes in the accepted values of the vapor pressure-temperature scale for helium and the less accurate methods of measurement that existed when his data was published。( 7 ) The Keesom data used in this paper was in general taken from his data of physical properties near the normal boiling point and is considered to be within his estimate of $3 \%$.

The Zelmanov study of the Joule--Thomson effect and his resulting temperature entropy diagram are estimated by Zelmanov to have an accuracy of within 3 per cent. Although in plotting one point it was found that a discrepancy of 25 per cent with Hill's data occurred at a pressure of 60 atmospheres and a specific volume of 6 liters per kilogram. Because this point was at the fringe of the Zelmanov area of investigation and because all other data of Zelmanov agreed to within 3 percent of the Hill data, the point was disregarded.

The work of Domb and Dugdale was used to establish the reference pressures when calculating isobars from Hill's data. The reference points were no longer needed after the data of Lounasmaa was received.

The data of Lounasmaa is considered within his estimate of 1 per cent because the experimental PVT data was of such scope as to eliminate inaccurate differentiations in finding derived PVT functions.

All other data cited are in agreement within the error mentioned above and therefore the overall accuracy of the plotted data of this paper is estimated to be within 5 per cent and possibly much less. 

Future investigations made possible by this paper include the extension of the temperature and pressure data to values greater than 20 degrees and 100 atmospheres. This could be done by correlation of the high pressure, high temperature data of Keesom with the data of this paper, using some type of equation of state. The result would be a very complete extensive composite diagram of state for helium. 



\section{BIB LIOGRAPHY}

(1) Berman, R. and C. F. Mate, "Some Thermal Properties of Helium and Their Relation to the Temperature Scale", Philosophical Magazine, (May, 1958), pp. 461-469.

(2) Domb, C., and J. S. Dugdale, "Solid Helium", Chapter XI, Progress in Low Temperature Physics, Volume II, Amsterdam, The Netherlands, North Holland Publishing Company, (1957), $480 \mathrm{pp}$.

(3) Hill, R. W., Personal Letter to R. B. Sc ott, Chief Cryogenic Engineering Laboratory, Boulder, Colorado, 7 October, 1957).

(4) Hill, R. W., and O. V. Lounasmaa, "The Specific Heat of Liquid Helium", Philosophical Magazine, (Feb., 1957), pp. $143-148$.

(5) "The Entropy Diagram of Helium", Fifth International Conference on Low Temperature Physics and Chemistry, Madison, Wisconsin, (26 August, 1957).

(6) Keesom, W. H., Helium, Ilsevier, (1942), 494 pp.

(7) Keesom, W. H., and K. Clusius, "Uber die Spezifische Warme des Flussigen", Leiden Communication, Number $219 \mathrm{e}$, Volume 35, (1932), pp. 42-58.

(8) Kramers, H., J. Wasscher, and C. Gorter, "The Specific Heat of Liquid Helium Between $0.25^{\circ}$ and $1.9^{\circ} \mathrm{K}^{\prime \prime}$, Physica, Volume 18, Number 5, (1952), pp. 329:-338.

(9) Lounasmaa, O. V., "Specific Heats at Low Temperatures", Thesis submitted for the Degree of Doctor of Philosophy, University of Oxford, (1958).

(10) Tsu, T. C., and D. T. Beecher, Thermodynamic Properties. of Compressed Water, ASME, (1957).

(11) Van Dijk, H., and M. Durieux, "The Temperature Scale in the Liquid Helium Region", Progress in Low Temperature Physics, Volume II, Amsterdam, The Netherlands, North Holland Publishing Company, (1957), 480 pp. 

(12) Zelmanov, J., "The Entropy Diagram for Helium at Low Temperatures", Journal of Physics (USSR), Volume 8, Number 3, (1944), pp. 135-141.

(13) "Joule-Thomson Effect in Helium at Low Temperatures", Journal of Physics (USSR), Volume 8, Number 1, (1940), pp. 43-52.

(14) Zemansky, M. W., Heat and Thermodynamics, Fourth Edition, New York, N.Y., McGraw-Hill Book Company, Inc., (1957), $484 \mathrm{pp}$.

(15) Clement, J. R., J.K. Logan, and J. Baffney, "Liquid Helium Vapor Pressure-Temperature Scale", Physical Review, Volume 100, (1955), p. 743. 

28.

APPENDIX 

Derived Functions and Diagram Construction

Figure 7 is the plot of isotherms on specific volume-entropy coordinates used in determining isobars. The data are from Hill, extended slightly by extrapolation at the lowest temperatures. Table III shows the data for this plot.

Slopes of the isotherms in Figure 7 were taken using a straightedge. These slopes $\left(\frac{\partial S}{\partial V}\right)_{T}$ were then plotted versus temperature, as example of which is shown in Figure 8. The integration was performed graphically using a temperature increment of $0.2^{\circ} \mathrm{K}$, and the resulting pressure differences were then based on fixed pressures from Table I.

Figure 9 is a plot of pressure and temperature showing isochores as determined from Figures 7 and 8 . The isentropic used in determining the enthalpy values is also shown. It was plotted using values determined from Figure 7. 

Page 30.

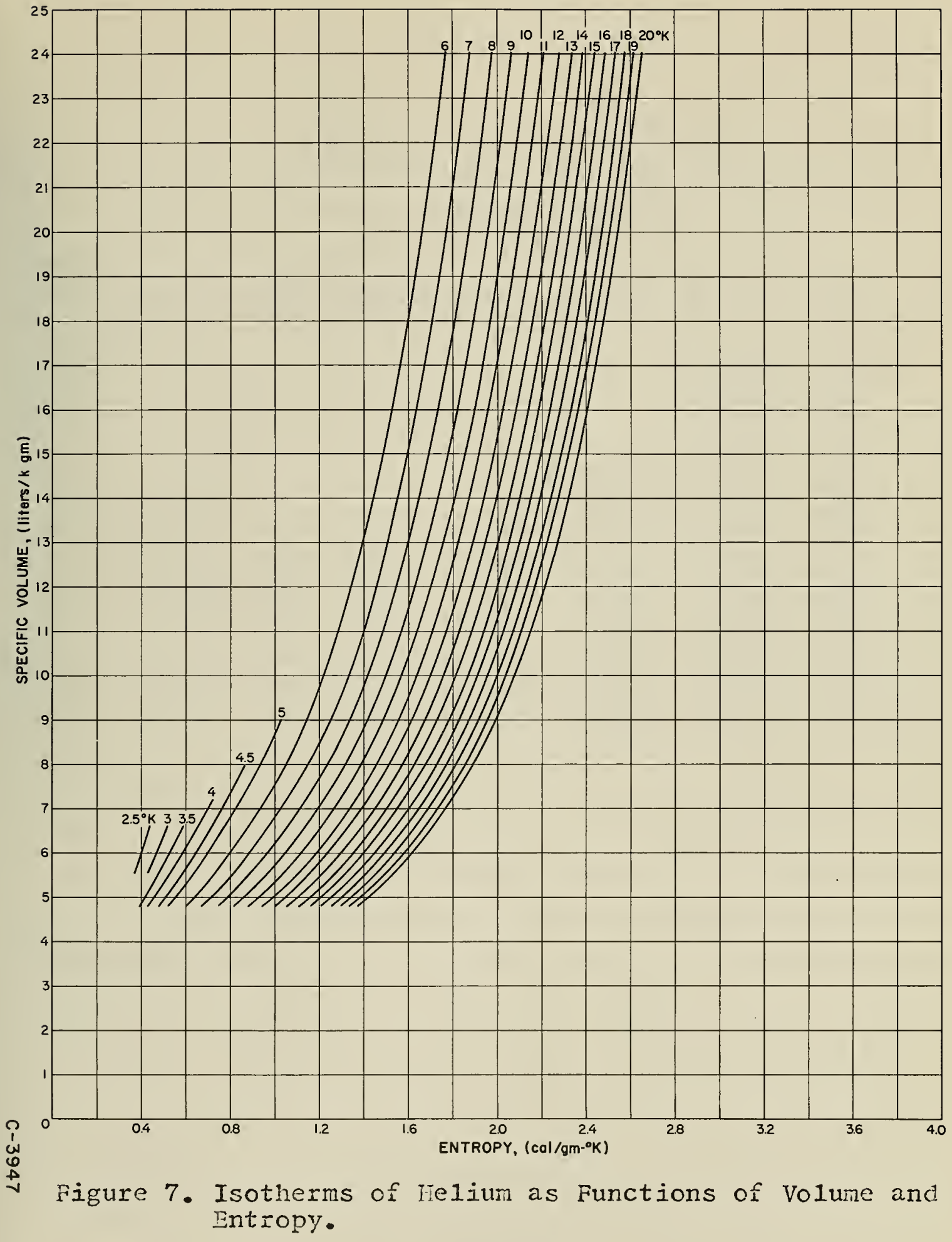



TABLE III (3)

\section{ENTROPY OF FLUID HELIUM}

Specific Volume

liters/kgm.

Temp.

${ }^{\circ} \mathrm{K}$

$72.15 \quad 24.05 \quad 14.43$

10.31

8.02

6.56

5.55

4.81

2.50

3.00

3.50

4.00

4.50

5.00

2. 152

6.00

7.00

2. 232

2. 367

2. 482

1.769

2. 580

1.883

1.462

1.980

1.573

1. 240

1.668

1. 345

2. 746

2. 143

1.828

1.438

1. 594

2. 276

1.960

1.724

3. 046

2. 440

2. 123

2. 654

2. 337

3. 260

1.866

15.00

20.00

2. 100

0.874

0.441

0.370

0.520

0.426

0.590

0.481

0.388

0.656

0.534

0.432

0.717

0.586

0.475

0.937

0.774

0.636

0.516

1.051

0.879

0.729

0.597

1.151

0.873

0.815

0.673

1.239

1.058

0.895

0.746

1.392

1. 205

1.037

0.880 *

1.520

1. 331

1. 160

$1.002 *$

1.681

1. 491

1. 319

1. $159 *$

1.894

1. 705

1. 533 *

1. $373 \%$

$\overline{\text { *Extrapolated Values }}$ 



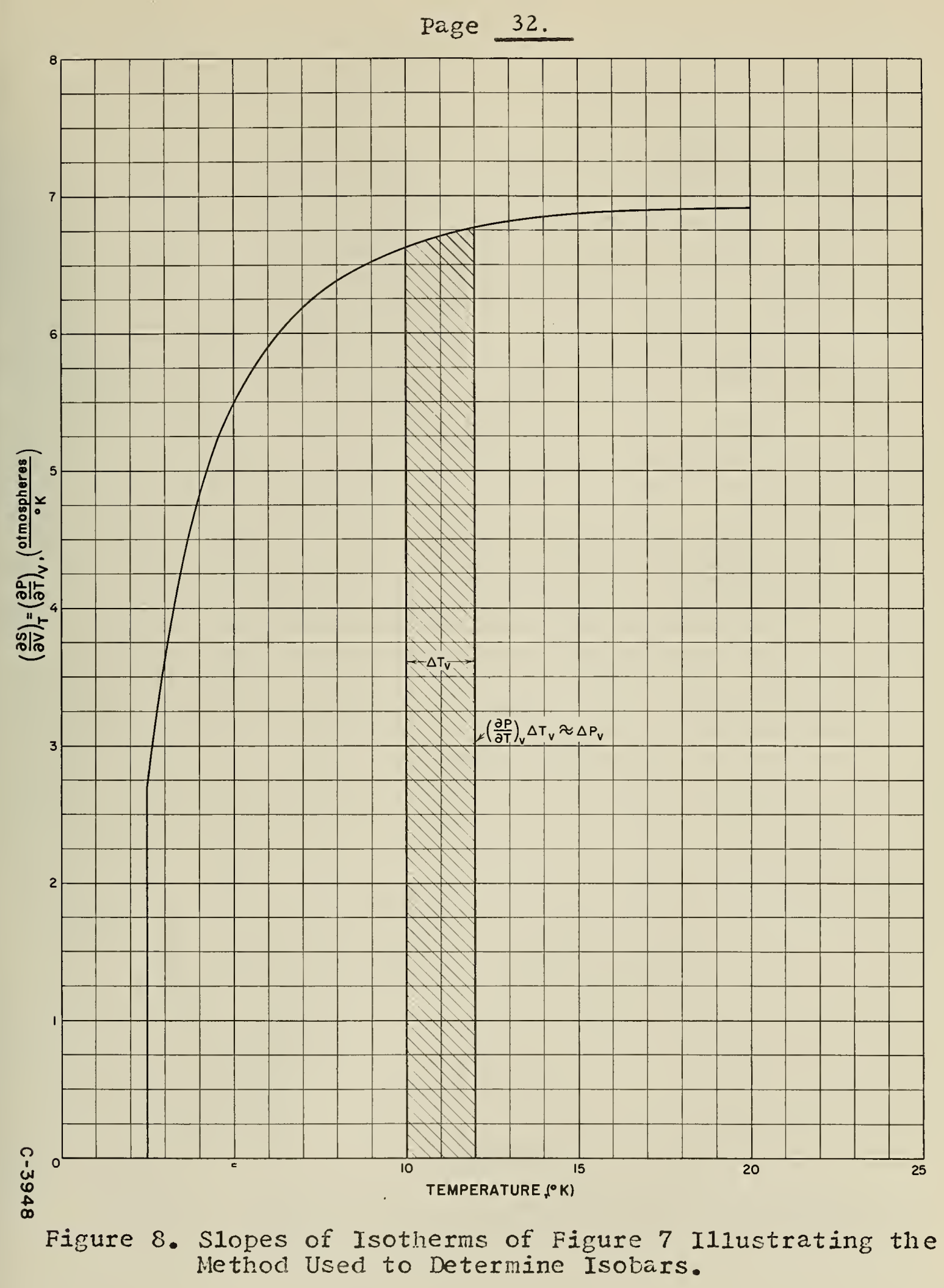



Page 33.

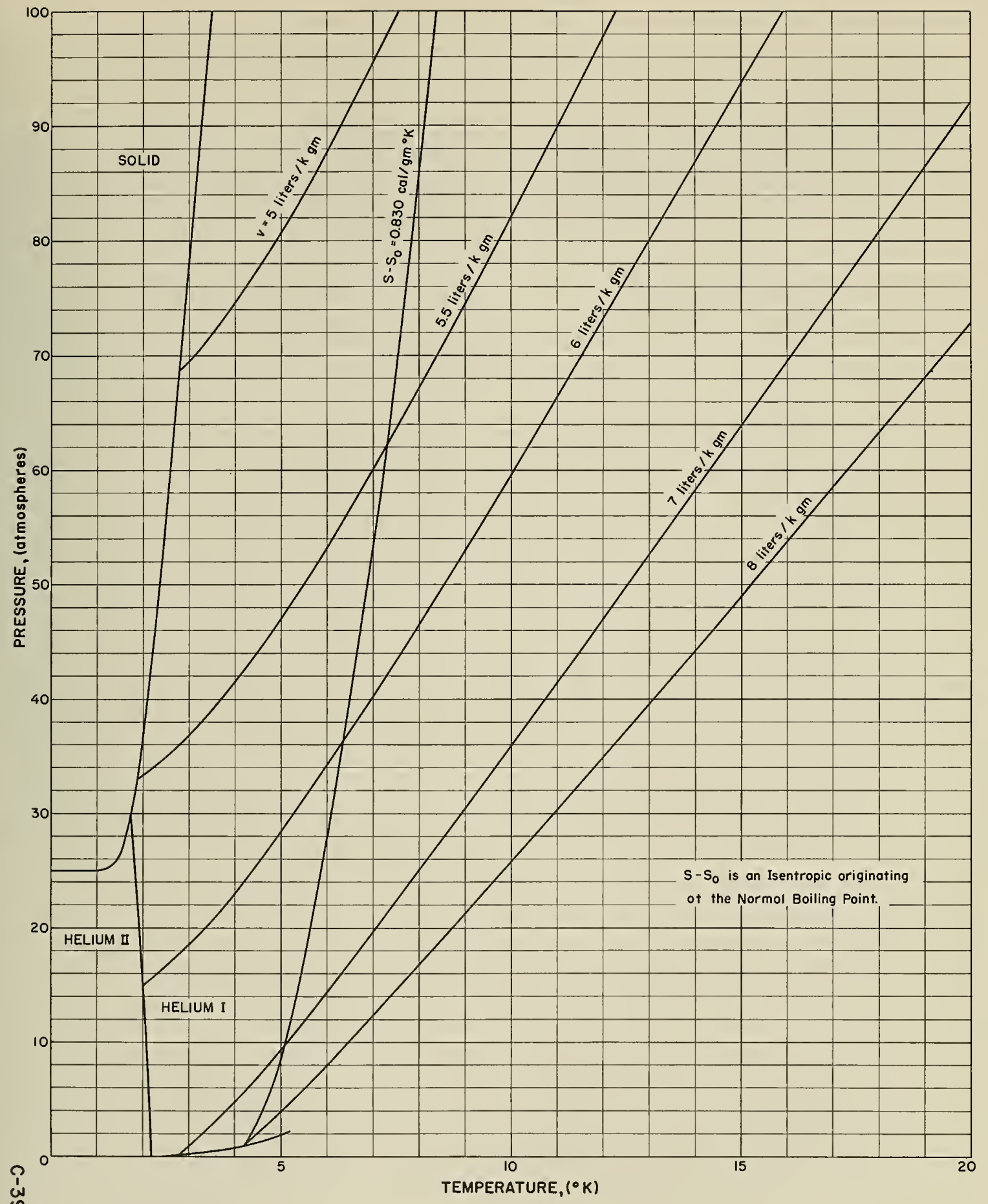

Figure 9.1ressure-Temperature Diagram of Helium Illustrating the Hethod Used to Determine Entha1py Values 

Associated Thermodynamic Properties Charts

The charts presented on the following pages were compiled from the data of Lounasmaa ${ }^{(9)}$ except in the $x$ temperature and pressure region of the vapor dome. Data for this region was taken from Bermanand Mate ${ }^{(1)}$ and Hill and Lounasmaa $(4)$. 

Page 35.

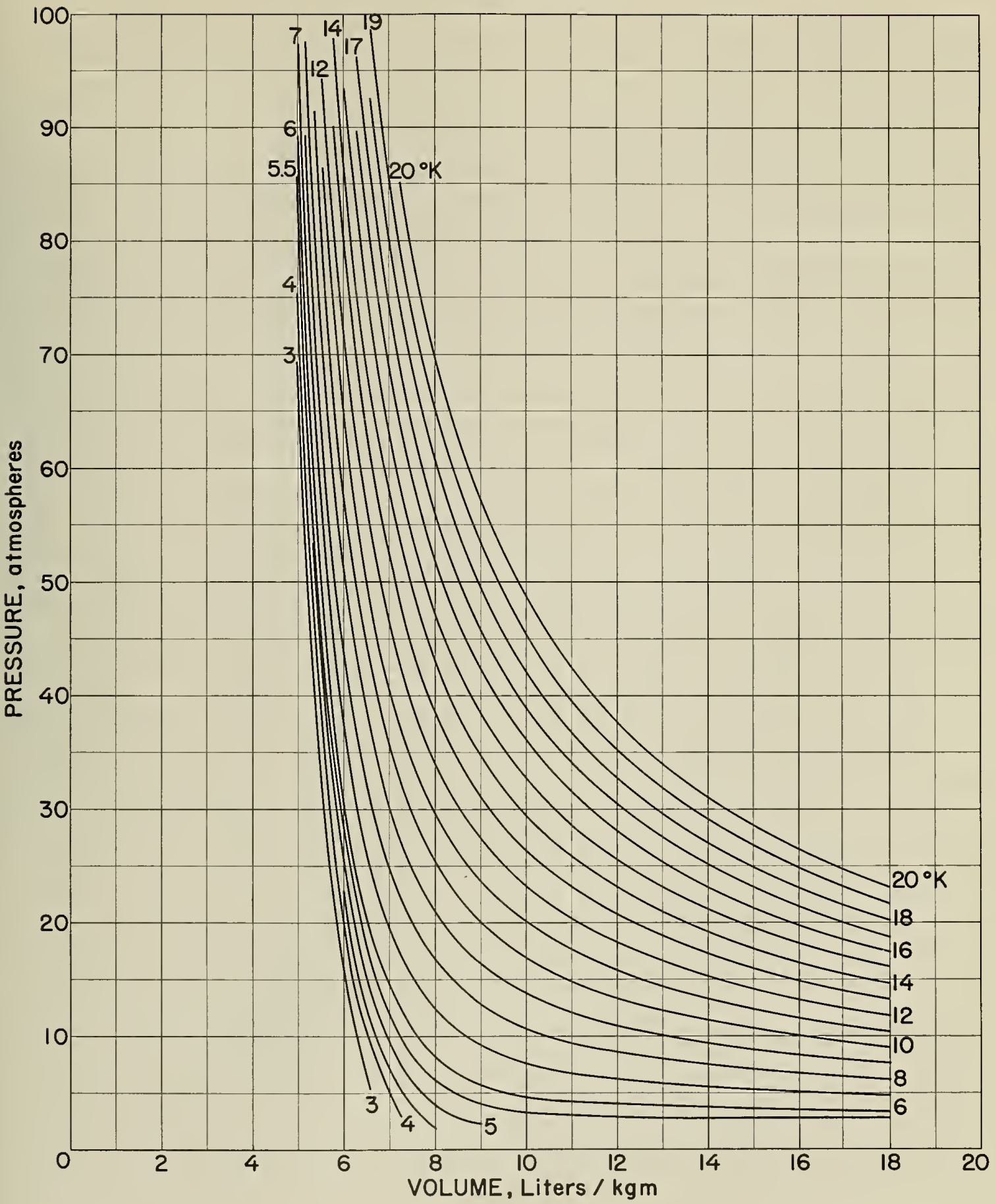

Figure 10. Fressure-Specific Volume Diagram for He Iium (Lounasmaa) 

Page 36.

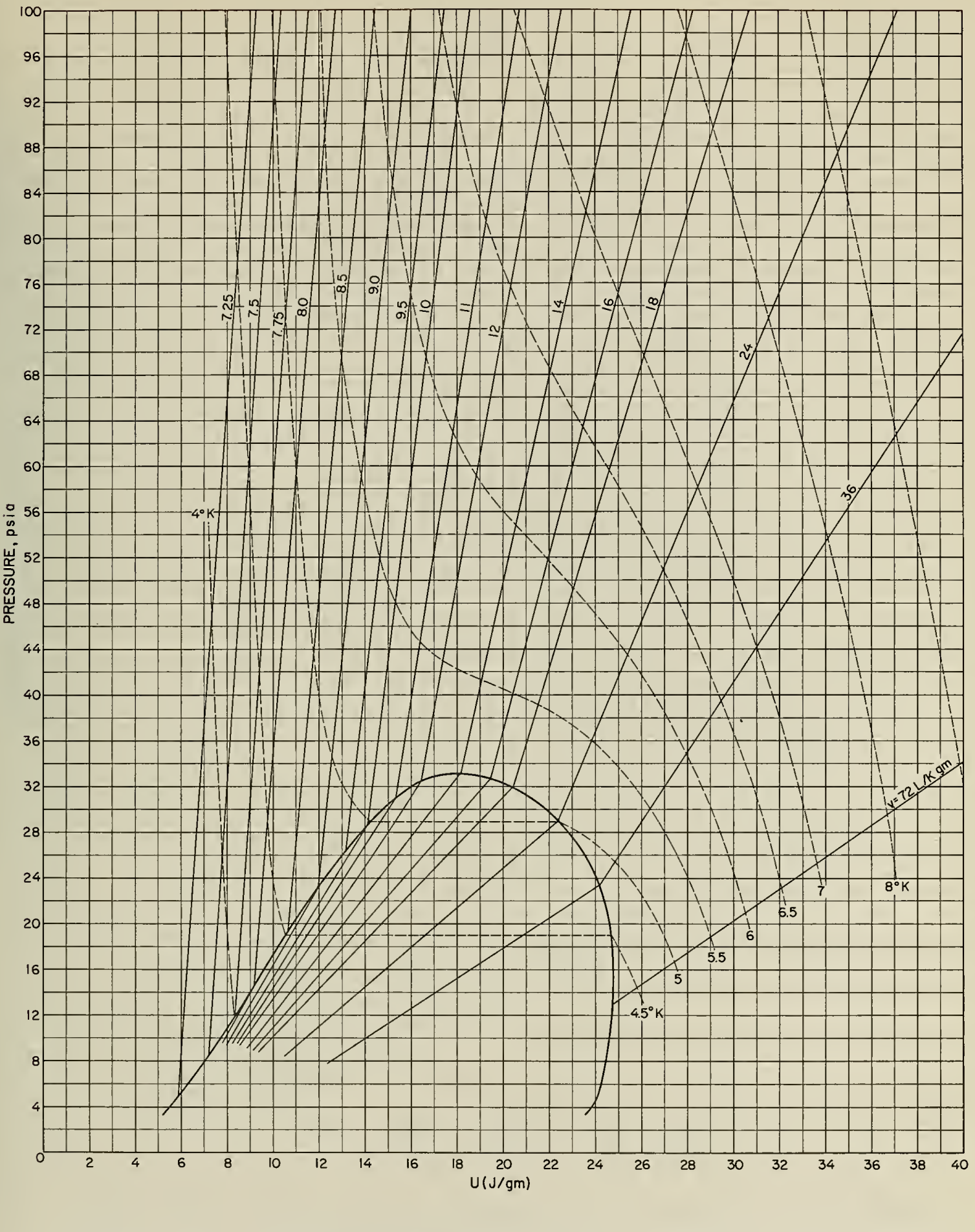

Fisure 11. Fressure-Internal Energy Jiagram for llelium 0 - 100 psia 

Page 37.

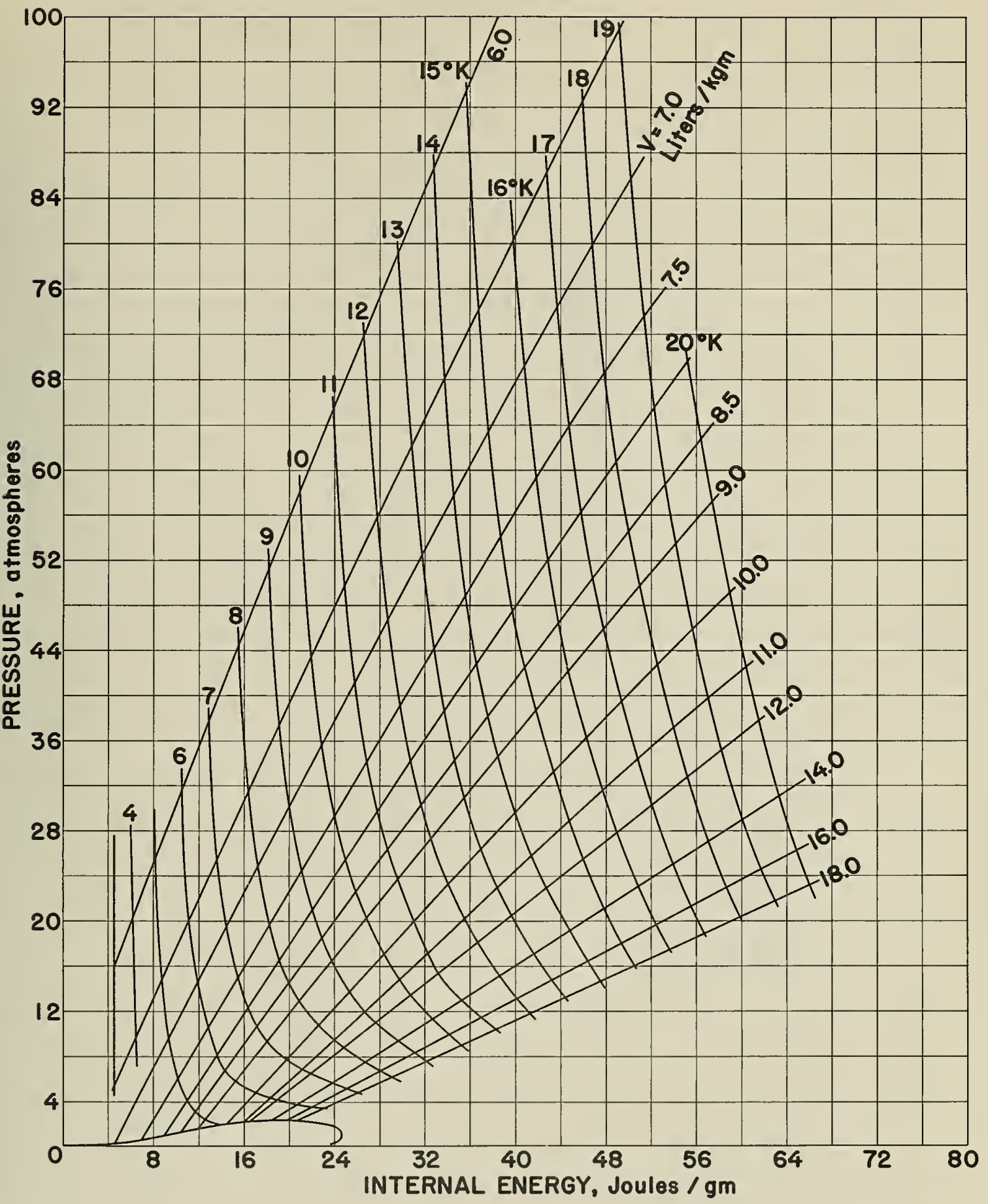

Figure 12. Fressure-Internal Energy Diagran for Telium 0 - 100 Atmospheres 

Page 38.

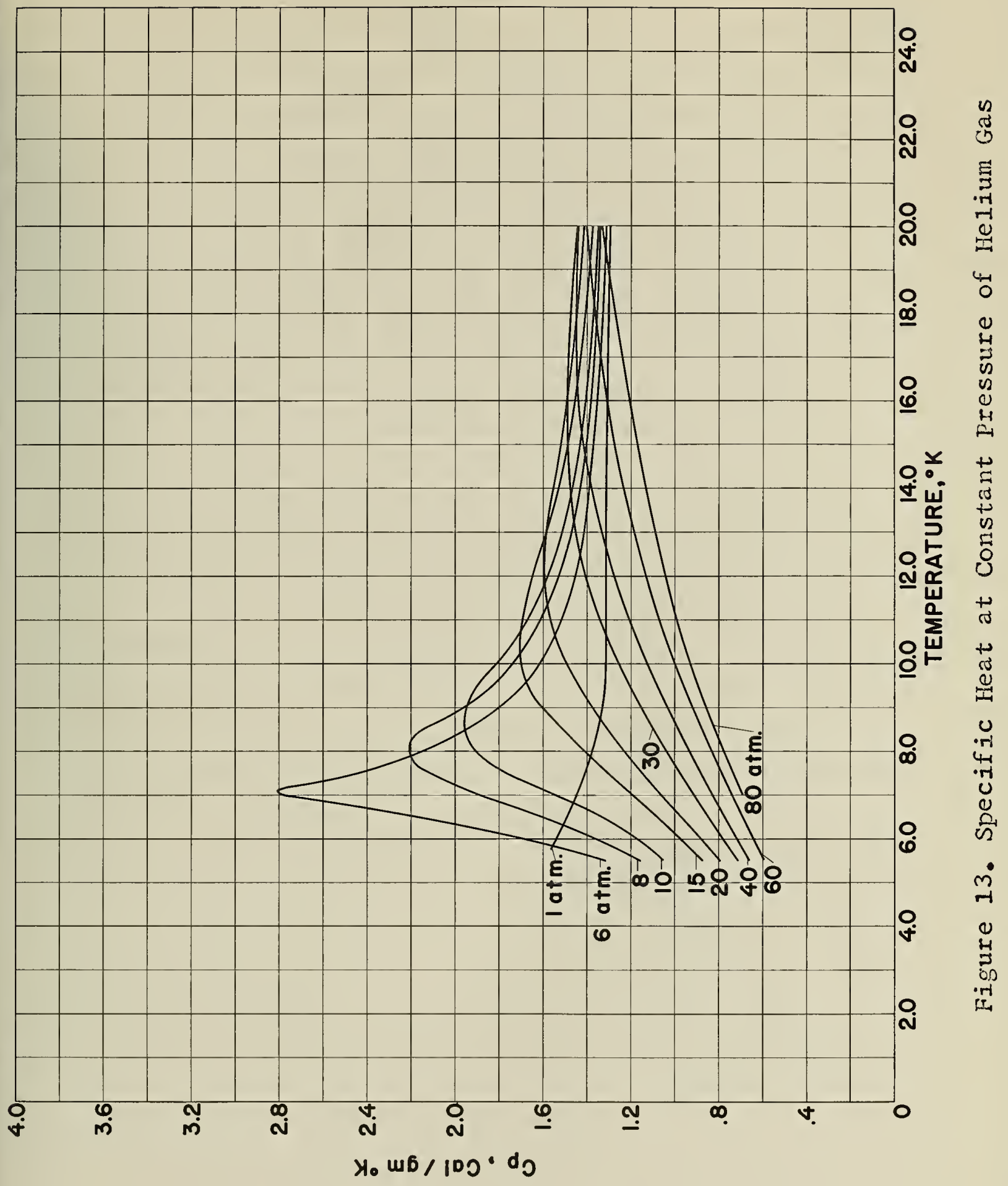



Page 39.

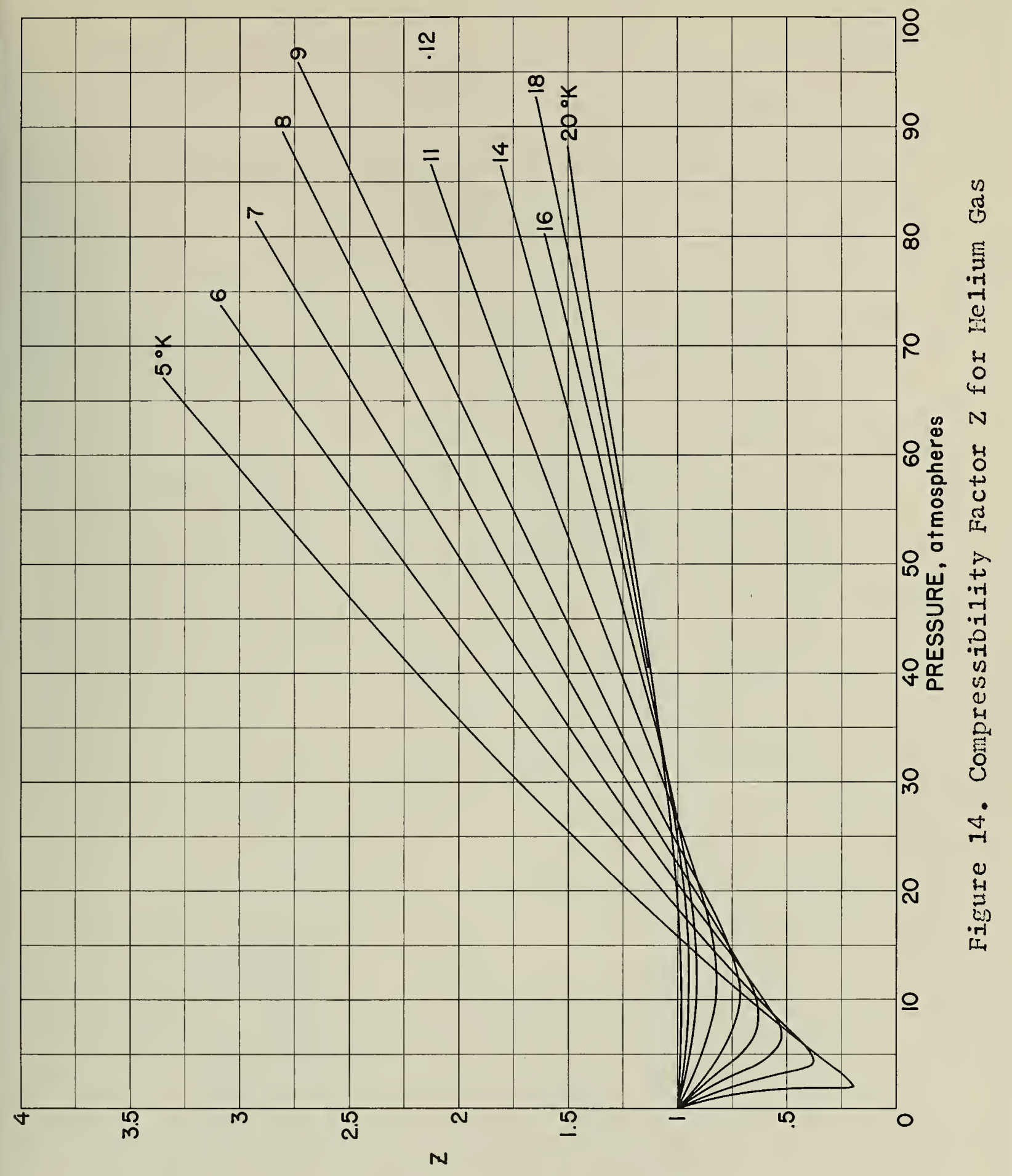






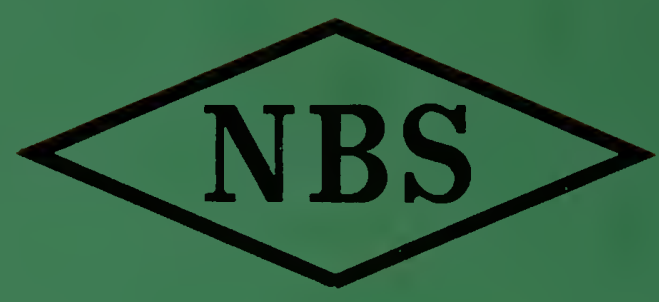

